\title{
METHODOLOGY FOR ASSESSMENT ACTIVITY OF THE TECHNOLOGY TRANSFER OFFICE BASED ON ANP
}

\author{
Rocío Poveda-Bautista* \\ Universitat Politècnica de València \\ Departamento de Proyectos de Ingeniería \\ Camino de Vera s/n 46022 Valencia (SPAIN) \\ E-mail: ropobau@upvnet.upv.es \\ Juan Pascual Pastor-Ferrando \\ Universitat Politècnica de València \\ Departamento de Proyectos de Ingeniería \\ Camino de Vera s/n 46022 Valencia (SPAIN) \\ E-mail: jppastor@dpi.upv.es \\ Pablo Aragonés-Beltrán \\ Universitat Politècnica de València \\ INGENIO (CSIC-UPV) \\ Ciudad Politécnica de la Innovación \\ Camino de Vera s/n 46022 Valencia (SPAIN) \\ E-mail: argones@dpi.upv.es \\ Fernando Jiménez Saéz \\ Universitat Politècnica de València \\ INGENIO (CSIC-UPV) \\ Ciudad Politécnica de la Innovación \\ Camino de Vera s/n 46022 Valencia (SPAIN) \\ E-mail: fjimenez@ingenio.upv.es
}

\begin{abstract}
The Technology Transfer Offices (TTOs) play an important role in the interconnection of Spanish Universities with its socioeconomic environment. In this paper an assessment which takes into account the results of the TTOs and analyzes the degree of alignment with the objectives set is carried out. The present work aims to design a methodology, based on the method Analytic Network Process Method (ANP), to evaluate the performance of the TTO. This method allows to set a priority between the different results obtained by the TTO and analyze the efficiency of public resources. This study will also include an analysis of the objectives of the TTO, the prioritizing them and analyzing the achievement of these objectives through various activities and actions undertaken by the TTO. This analysis should be useful to managers to determine which actions contribute, and to what extent, the achievement of objectives and which ones should be removed, modified or enhanced to improve the level of achievement.
\end{abstract}

Keywords: Technology Transfer Offices (TTOs), Analytic Hierarchy Process (AHP), Analytic Network Process (ANP).

\footnotetext{
* Corresponding author
} 
Acknowledgments: supported with project Proposal of valuation model patents generated by researchers through multicriteria techniques AHP and ANP PAID-05-11/ from Universitat Politècnica de València

\section{Introduction}

The university was founded in the twelfth century, with a mission to transfer university faculty's knowledge to the students. Since then it has experienced an evolution and has changed it from being a repository of scientific knowledge and isolated from society, to a new position in the socio-economic environment in which it operates as an agent of national and local development (Geuna, 1998). According to Etzkowitz et al. (2000, 2003), the university has experienced an evolution in its goals becoming more and more committed with society.

Today, the new knowledge plays a substantial role in the process of economic and social innovation, consequently it is of paramount importance that universities and research centers play an increasingly important role.

The relationship between universities and their socio-economic environment can be defined as the set of processes and practices that lead to technology transfer mechanisms, in which the academic and administrative elements of the university are related to each other and to other agents in order to develop and implement actions and projects for the benefit of society. (Gould, 1997). Technology transfer mechanisms are the practical means by which universities interact with their socio-economic environment.

Among the latest technology transfer mechanisms we can mention spin-off and joint-venture companies, promoters of science (research and technology) centers and enterprises. They complement and strengthen traditional mechanisms such as training programs for human resources, academic consulting, scientific and technological services, recruitment of future professionals, contracted research projects, technological innovation, use of university facilities, exploitation of licensed inventions, among others (Huanca, 2004, Lee et al., 2004; Stephan, 2001)

The relationship between Spanish Universities and the socioeconomic environment takes place through their Technology Transfer Offices (TTO), facilitating collaboration and agreements between researchers from universities and companies, helping to find sources public funding for joint projects, disseminating research results and managing patents developed in universities and exploited by external companies.

In most Spanish public universities, the activities and management capacity of the TTOs have increased dramatically in recent years, which also involves a significant use of resources. For this reason it is of great interest to evaluate the extent to which these institutions are fulfilling their mission, even if it is diverse both in the contexts in which it operates and the variety of agents, mechanisms and fields of knowledge involved.

Although the three missions of universities (education, research and relationship with the socioeconomic environment) have been present since the beginning, their relative weight has varied over time and by type of university (Martin, 2003). In recent years there has been a growing demand from many governments both in industrialized and developing countries, leading universities to have a more active role in contributing to economic growth and development (Leydesdorff and Etzkowitz, 1996; Clark, 1998). This demand has resulted in the 


\section{R. Poveda-Bautista et al./ Methodology for assessment activity}

implementation of many initiatives to encourage the strengthening of ties between universities and society.

Moreover, there are great differences among Technology Transfer Offices (TTO) not only due to their particular contexts and type of university, but also to the tools and systems used. Therefore, the determination of the indicators of knowledge transfer activities has to take all this diversity into consideration. This work addresses the need for specificity in the generation of indicators (criteria) for the assessment of the activity of Spanish TTOs.

Up to now no thorough evaluation of TTO activities has been developed. Research on this topic is scarce and no practical approach has been found that applies to university TTOs and serves as a basis for measuring and evaluating the results of their activity.

The aim of this paper is to propose a method to analyze the degree of alignment between TTO objectives recognized in their mission as part of the function they perform for the university to which they belong and the actions actually undertaken by the organization to achieve such objectives. The model will reveal to what extent these actions meet the objectives of the TTO and will serve to measure TTO efficiency. This will enable academic authorities to modify policies and action plans in case of deviations.

For the development of the methodology we requested the cooperation of the TTO of the Polytechnic University of Valencia which served as a model of a Spanish university with a high number of technology transfer activities

\section{Background of MCDM. AHP and ANP techniques.}

The Analytic Hierarchy Process (AHP) and the Analytic Network Process (ANP) are two methods proposed by Saaty $(1980,2001)$ that belong to the field of Multi-Criteria Decision Analysis (MCDA). Each technique is used for those steps of the model where it presents more advantages.

In the present work the AHP method is used to assign priorities to the TTO's objectives regarding its environment.

AHP is conceptually easy to use; its strict hierarchical structure however cannot handle the complexities of many real world problems. As a solution, Saaty proposed ANP, the general form of AHP, which allows us to represent a network model of the TTO's objectives and action plans and the interdependences among them. ANP represents a decision making problem as a network of criteria and alternatives (all called elements), grouped into clusters.

The ANP-based approach has been used in this work to analyse the relationships between TTO's objectives and resulting action plans and the socio-economic environment for the following reasons: (i) prioritization of objectives is a multicriteria decision problem, (ii) some of the objectives used in the prioritization process are intangible and therefore difficult to weight by common methods (iii) there may exist interdependences among TTO's objectives and between its objectives and the actions taken to achieve them.

The ANP technique has already been applied to different decision-making problems, for example, for measuring knowledge management in a company and compare it with that of other competitors (Huang et al., 2007), financial crisis forecasting (Niemira and Saaty, 2004), determination of appropriate energy policies (Haktanırlar, 2005), selection of R\&D projects 
Proceedings of the International Symposium on the Analytic Hierarchy Process 2013

(Mohanty et al, 2005), in the field of public policies, (Haktanırlar, 2005; Wolfslehner and Vacik, 2008). However, no application to analyse TTO's objectives has been reported yet. 


\section{Proposed Methodology}

\subsection{Step 1: Formulation of the problem}

The first step of the process is to collect information to gain a deeper understanding of the objectives and actions developed by the TTO with the purpose of linking the university with its socio-economic environment. The mission of the university is to contribute to socio-economic development through scientific, technical and administrative support, as well as objectives, strategies and action plans identified in its strategic plan for the fulfillment of this mission This approach is based on the mission, vision and values of the University that motivate its goals, policies and action plans identified in its strategic plan regarding its TTO mission of promoting and facilitating knowledge generation and dissemination and transfer to society of the knowledge generated.

\subsection{Step 2: Selection of the panel of experts}

In order to obtain better results, it is advisable for a group of experts to take part in the process of solving the problem of prioritization (Aragonés, 2001); the experts will act as "decisionmakers". For the purpose of this study it is recommended for the expert team to take part in the definition of the objectives and actions of the TTO. It is generally recommended that experts be selected based on their knowledge and experience in the university's relationship with the socio-economic environment as well as the time available to participate in the study (Goodwin and Wright, 2004).

After having been informed about the study, they will collaborate in determining the influences that exist between all ANP elements.

\subsection{Step 3: Determination of the objectives}

Using the information on the objectives collected in Step 1 and through interviews with the panel of experts, the TTO objectives relative to its mission within the university were identified. As many interviews as necessary were conducted to ensure that the experts achieved consensus on the TTO objectives.

Below is the list of the objectives defined by the group of experts regarding the TTO mission of promoting and facilitating knowledge generation and fostering dissemination and transfer to society of the knowledge generated:

1. Facilitating participation of the university in publicly-funded R\&D\&I programs

2. Orienting research or technical support activities that are developed by external companies or other entities.

3. Valuing and transferring R\&D\&I results

4. Management of research activities

5. Scientific dissemination.

\subsection{Step 4: Prioritization of TTO Objectives}

Following the AHP approach, each expert must assign an importance value to each objective stated. For that purpose and according to the AHP method, he/she must make a series of binary comparisons between the objectives defined in Step 3, issuing their judgements individually $\left(\mathrm{a}_{\mathrm{ij}}\right)$ according to their knowledge and experience using Saaty's scale.

$\mathbf{a}_{\mathrm{ij}}=\mathbf{1}$ : objective $\mathrm{i}$ and objective $\mathrm{j}$ are considered equally important

$\mathbf{a}_{\mathrm{ij}}=\mathbf{3}$ : objective $\mathrm{i}$ is considered slightly more important than objective $\mathrm{j}$

$\mathbf{a}_{\mathrm{ij}}=\mathbf{5}$ : objective $\mathrm{i}$ is considered considerably more important than objective $\mathrm{j}$ 
$\mathbf{a}_{\mathrm{ij}}=\mathbf{7}$ : objective $\mathrm{i}$ is considered much more important (or demonstrably more important) than objective $\mathrm{j}$

$\mathbf{a}_{\mathrm{ij}}=$ 9: objective $\mathrm{i}$ is considered absolutely more important than objective $\mathrm{j}$

The questionnaire designed for this purpose is very important (See Annex 1). Once the experts have completed the questionnaires for the prioritization of the objectives according to the AHP method, a single value of the priorities of the TTO objectives is obtained by integrating the priorities given by the experts and calculating the geometric mean (Saaty, 1980).

The analytic hierarchy model obtained for the prioritization of TTO objectives is shown in Figure 1.

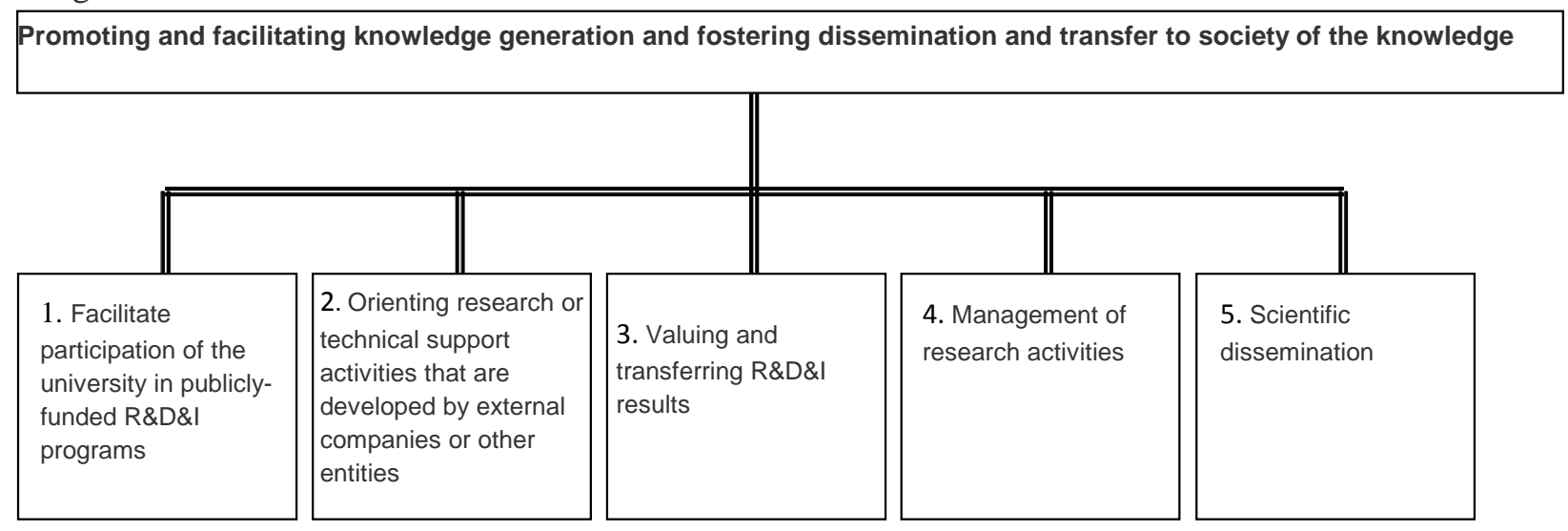

Figure 1. Prioritization of objectives using AHP

\subsection{Step 5: Determination of Action plans}

The information collected in Step 1 and in the interviews with the panel of experts also served to identify the action plans developed by the TTO to achieve the objectives. These plans should include those actions conducted by the TTO that contribute to the achievement of the objectives. As many interviews as necessary were conducted to ensure that the experts achieved consensus on the TTO action plans.

The action plans should be specifically defined for each TTO to which the methodology is applied.

\subsection{Step 6: Definition of the ANP model}

Using the resulting information on the TTO actions and objectives relative to its mission, a model of the problem is built using the following analogies that will allow us to model the decision problem as an ANP network. The objectives were grouped into a single cluster and the action plans were grouped into five clusters (clusters of action plans): Dissemination, promotion and marketing, Guidance and negotiation, Administrative management, Financial management and Management of research results and capabilities.

\begin{tabular}{|l|c|}
\hline Components of the ANP network & Equivalence in the TTO model \\
\hline Criteria clusters & 5 Action-Plans clusters: \\
& - Dissemination, promotion and \\
& marketing \\
& - Adidance and negotiation \\
& - Financial management \\
& - Management of research results and \\
& capabilities \\
\hline
\end{tabular}




\begin{tabular}{|l|l|}
\hline Elements of the criteria clusters & Action Plans (Step 5) \\
\hline Cluster of alternatives & Cluster of Objectives \\
\hline Elements of the alternatives cluster & Objectives (Step 3) \\
\hline
\end{tabular}

Table 1. Equivalence between Components of the ANP network and TTO model

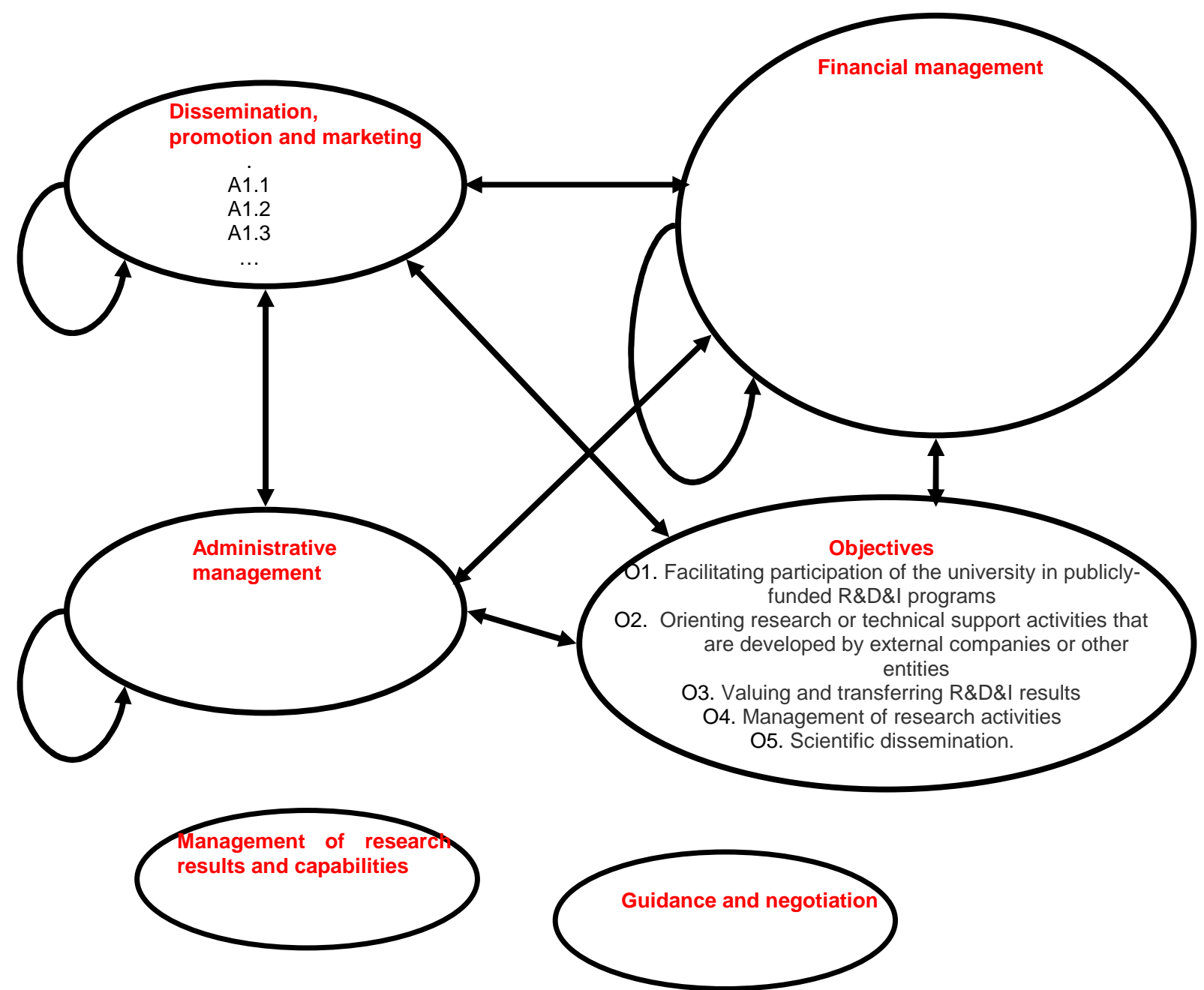

Figure 2. ANP-based modeling of the alignment problem.

In order to determine the influences among the components of the network Saaty proposes the use of an influences matrix that allows the structured analysis of all influences among the elements in the network. As many interviews as necessary were conducted to ensure that the experts achieved consensus on the influences matrix.

\subsection{Step 7: Prioritization of objectives using ANP}

ANP has been described as a single step in the proposed methodology whose purpose is to obtain the total weights of the objectives of the TTO (alternatives in the ANP model), in relation to its mission, taking into consideration all influences identified in the network.

\section{(i) Calculation of priorities between elements}

The first task is the calculation of priorities between elements, i.e. between action plans and objectives, provided there exists some relationship between the elements, represented in the network model by an arrow that connects the components to which they belong and indicated in 
the influences matrix by a non-zero entry. Pairwise comparison matrices are used for the calculation of priorities.

For this purpose, a questionnaire covering the five action-plan clusters (Dissemination, promotion and marketing, Guidance and negotiation, Administrative management, Financial management, Management of research results and capabilities) is designed to be answered by the experts of each TTO unit. Each part of the questionnaire will be completed with the necessary information based on the experts' knowledge and experience to obtain the influences for each criterion indicating which actions have influence on or affect the action plans developed by the expert's unit.

Experts should review their answers if the consistency index of their judgments is above $10 \%$.

\section{(ii) Construction of the original supermatrix}

All this data allows us to build the supermatrix, one of the main features of the ANP method. The supermatrix is used to gather all information regarding the influence of the elements of one component on themselves (feedback) or on the elements of the other components of the system (interdependence).This supermatrix allows us to obtain the normalized components of the priority vectors between the elements calculated in task (i) calculation of priorities between elements.

\section{(iii) Determination of the weighted supermatrix}

The calculation of the weighted supermatrix is necessary for the calculation of the limit supermatrix. For this purpose, the priority vectors between components calculated in task (ii) of Step 7 are used.

\section{(iv) Calculation of the limit supermatrix}

Once we have obtained the weighted supermatrix, we can calculate the limit supermatrix. The procedure consists of raising the weighted supermatrix to successive powers until their entries converge to a certain value. When this is reached, all columns of the supermatrix are equal, i.e. a column-stochastic matrix. The values of the columns indicate the overall priority of all network elements: TTO actions and objectives.

\section{(v) Determination of objective priorities}

From the limit supermatrix it is possible to know the overall priorities of all network elements, which were calculated taking into account the direct and indirect influences between the elements of the system. TTO objectives and action plans are the elements of the system (as shown in Table 1) and are therefore included in the supermatrix. To obtain the prioritization of the elements it suffices to retrieve the information from their weights in the limit supermatrix.

\subsection{Step 8: Alignment analysis}

In the last step of the process the results of the theoretical prioritization of TTO objectives identified by the experts (based on AHP), Step 4, are compared with the experts' prioritization of objectives considering the action plans developed by the TTO (based on ANP), Step 7.

This last step also allows us to obtain a rough measure of the level of contribution or influence of each action on each action-plan cluster. 
Considering these two prioritizations of objectives, the question 'Are TTO objectives aligned with the outcomes reached through the action plans related to its mission?' can be answered.

Comparing the prioritization of preferences on the objectives (in accordance with TTO mission defined in the strategic plan of the university) with the prioritization of the influences of the action plans on the objectives (real case), reveals the degree of misalignment of some TTO objectives.

In Step 4 of the methodology a theoretical prioritization of objectives was obtained. They are compared with the degree of achievement of the objectives met through the actions described in Step 7.

\section{Conclusions}

In this paper we have shown an approach to address such complex problems as measuring the alignment of strategic objectives of a university to its socioeconomic environment based on the results of the actions taken by the TTO for the achievement of the objectives.

The Analytic Hierarchy Process has been used to obtain the theoretical prioritization of the objectives of the university whereas the Analytic Network Process has allowed us to prioritize them based on the actual results of the actions taken by the TTO for the achievement of the objectives.

The comparison of the AHP-based prioritization of objectives with the ANP-based prioritization makes it possible to determine the degree of alignment of the university's objectives to its socioeconomic environment. If a misalignment is detected the university will have to apply corrective policies in order to achieve its theoretical objectives.

The results obtained will be of great value for decision-making in university policies concerning technology transfer strategies between the university and its local community.

The authors of this work also want to highlight the deep analysis of the objectives and their degree of importance according to different experts.

Finally, it must be pointed out that AHP and ANP can be used for a wide range of applications in universities. These techniques can be used to help solve complex prioritization and decisionmaking processes that are typically found in the university community. As an illustration we can mention a few applications: evaluation of the merits of faculty members, university strategy planning; evaluation of research papers, distribution of the university budget, redesigning the curricula of Master's degrees, selection of teaching staff, evaluation of the effectiveness of the different teaching techniques for meeting training goals, allocation of university resources, information management, infrastructure and facilities planning, among others.

\section{ANNEX 1: Questionnaire: AHP criteria weighting}

For each pair of criteria please indicate highlighting in black which of the two you consider to be most important and to what extent.

The criteria must be compared pairwise, asking to what degree criterion $\mathrm{C}_{\mathrm{i}}$ is better compared with criterion $\mathrm{C}_{\mathrm{j}}$, using the following scale (Saaty's scale):

$\mathrm{Cij}=1$ : criterion $\mathrm{i}$ and criterion $\mathrm{j}$ are considered equally important

$\mathrm{Cij}=3$ : criterion $\mathrm{i}$ is considered slightly more important than criterion $\mathrm{j}$

$\mathrm{Cij}=5$ : criterion $\mathrm{i}$ is considered considerably more important than criterion $\mathrm{j}$

$\mathrm{Cij}=7$ : criterion $\mathrm{i}$ is considered much more important ( or demonstrably more important) than criterion $\mathrm{j}$

$\mathrm{Cij}=9$ : criterion $\mathrm{i}$ is considered absolutely more important than criterion $\mathrm{j}$

O1: Facilitating participation of the university in publicly-funded R\&D\&I programs

O2: Orienting research or technical support activities that are developed by external companies or other entities. 


\begin{tabular}{|l|l|l|l|l|l|}
\hline Which objective do you consider more important? & O1 & O2 & \multicolumn{4}{|l|}{$\mid$} \\
\hline To what extent? & 1 & 3 & 5 & 7 & 9 \\
\hline
\end{tabular}

O1: Facilitating participation of the university in publicly-funded R\&D\&I programs O3: Valuing and transferring R\&D\&I results

\begin{tabular}{|l|l|l|l|l|l|}
\hline Which objective do you consider more important? & O1 & O3 & \multicolumn{4}{|l|}{$\mid$} \\
\hline To what extent? & 1 & 3 & 5 & 7 & 9 \\
\hline
\end{tabular}

O1: Facilitating participation of the university in publicly-funded R\&D\&I programs

O4: Management of research activities

\begin{tabular}{|l|l|l|l|l|l|}
\hline Which objective do you consider more important? & O1 & O4 & \multicolumn{4}{|l|}{} \\
\hline To what extent? & 1 & 3 & 5 & 7 & 9 \\
\hline
\end{tabular}

O1: Facilitating participation of the university in publicly-funded R\&D\&I programs

O5: Scientific dissemination

\begin{tabular}{|l|l|l|l|l|l|}
\hline Which objective do you consider more important? & O1 & O5 & \multicolumn{4}{|l|}{} \\
\hline To what extent? & 1 & 3 & 5 & 7 & 9 \\
\hline
\end{tabular}

O2: Orienting research or technical support activities that are developed by external companies or other entities O3: Valuing and transferring R\&D\&I results

\begin{tabular}{|l|l|l|l|l|l|}
\hline Which objective do you consider more important? & O2 & O3 & \multicolumn{4}{|l|}{} \\
\hline To what extent? & 1 & 3 & 5 & 7 & 9 \\
\hline
\end{tabular}

O2: Orienting research or technical support activities that are developed by external companies or other entities O4: Management of research activities

\begin{tabular}{|l|l|l|l|l|l|}
\hline Which objective do you consider more important? & $\mathrm{O} 2$ & $\mathrm{O} 4$ & \multicolumn{4}{|l|}{} \\
\hline To what extent? & 1 & 3 & 5 & 7 & 9 \\
\hline
\end{tabular}

O2: Orienting research or technical support activities that are developed by external companies or other entities O5: Scientific dissemination

\begin{tabular}{|l|l|l|l|l|l|}
\hline Which objective do you consider more important? & O2 & O5 & \multicolumn{4}{|l|}{} \\
\hline To what extent? & 1 & 3 & 5 & 7 & 9 \\
\hline
\end{tabular}

O3: Valuing and transferring R\&D\&I results

O4: Management of research activities

\begin{tabular}{|l|l|l|l|l|l|}
\hline Which objective do you consider more important? & O3 & O4 & \multicolumn{4}{|l|}{$\mid$} \\
\hline To what extent? & 1 & 3 & 5 & 7 & 9 \\
\hline
\end{tabular}

O3: Valuing and transferring R\&D\&I results

O5: Scientific dissemination

\begin{tabular}{|l|l|l|l|l|l|}
\hline Which objective do you consider more important? & O3 & O5 & \multicolumn{4}{|l|}{$\mid$} \\
\hline To what extent? & 1 & 3 & 5 & 7 & 9 \\
\hline
\end{tabular}

O4: Management of research activities

O5: Scientific dissemination

\begin{tabular}{|l|l|l|l|l|l|}
\hline Which objective do you consider more important? & O4 & O5 & \multicolumn{4}{|l|}{$\mid$} \\
\hline To what extent? & 1 & 3 & 5 & 7 & 9 \\
\hline
\end{tabular}




\section{REFERENCES}

Aragonés, P., Gómez-Senent, E., Pastor, J., Ordering the Alternatives of a Strategic Plan of Valencia (Spain). Journal of Multicriteria Decision Analysis 2001, 10 (3), pp. 153-171.

Etzkowitz H., Leydesdorff L. (2000); The dynamics of innovation: from National Systems and "Mode 2" to a Triple Helix of university-industry-government relations, Research Policy 29, pp. 109-123.

Etzkowitz, H. (2003); Research groups as 'quasi-firms': the invention of the entrepreneurial university, Research Policy 32, pp. 109-121.

Geuna, A. (1998); The internationalization of European universities: a return to medieval roots. Minerva XXXVI (3), pp. 253-270.

Goodwin, P., Wright, G. (2004); Decision Analysis for Management Judgment. John Wiley and Sons.

Gould, G.B. (1997); Vinculación universidad - sector productivo: una reflexión sobre la planeación y operación de programas de vinculación, ANUIES, Universidad Autónoma de Baja California, México.

Haktanırlar, B. (2005); Determination of the appropriate energy policy for Turkey, Energy 30, pp. 1146-1161.

Huanca, R. (2004); La investigación universitaria de países en desarrollo y la visión de los académicos sobre la relación universidad empresa: Universidades públicas de la región occidental de Bolivia, Tesis Doctoral, Universidad Politécnica de Valencia, Valencia (España)

Niemira, M. P., Saaty, T. L. (2004); An Analytic Network Process model for financial-crisis forecasting, International Journal of Forecasting 20, pp. 573-587

Saaty, T.L. (1980); The Analytic Hierarchy Process, McGraw-Hill, New York, NY.

Saaty, T.L. (2001); The Analytic Network Process; Decision Making with Dependence and Feedback ( 2 ed.); Pittsburg: RWS Publications.

Stephan, P. E. (2001); Educational Implications of University/Industry Technology Transfer, Journal of Technology Transfer 26, pp. 199-205. 